\title{
Remote ischemic preconditioning in cyanosed neonates undergoing cardiopulmonary bypass: A randomized controlled trial
}

\author{
Bryn O. Jones, MBBS, FRACP, ${ }^{\mathrm{a}, \mathrm{b}, \mathrm{c}}$ Salvatore Pepe, $\mathrm{PhD},{ }^{\mathrm{b}, \mathrm{c}}$ Freya L. Sheeran, PhD, ${ }^{\mathrm{b}, \mathrm{c}}$ \\ Susan Donath, MA, ${ }^{\mathrm{d}}$ Pollyanna Hardy, MSc, ${ }^{\mathrm{e}}$ Lara Shekerdemian, MD, ${ }^{\mathrm{f}}$ Daniel J. Penny, MD, PhD, ${ }^{\mathrm{g}}$ \\ Ian McKenzie, MBBS, FANZCA, ${ }^{\text {b,c,h }}$ Stephen Horton, PhD, ${ }^{\text {,c, }, \mathrm{i}}$ Christian P. Brizard, MD,, ,c,i \\ Yves d'Udekem, MD, PhD, ${ }^{\text {b,c,i }}$ Igor E. Konstantinov, $\mathrm{MD}, \mathrm{PhD},{ }^{\mathrm{b}, \mathrm{c}, \mathrm{i}}$ and \\ Michael M. H. Cheung, MB, ChB, MD ${ }^{\mathrm{a}, \mathrm{b}, \mathrm{c}}$
}

Objective: The myocardial protective effect of remote ischemic preconditioning has been demonstrated in heterogeneous groups of patients undergoing cardiac surgery. No studies have examined this technique in neonates. The present study was performed to examine the remote ischemic preconditioning efficacy in this high-risk patient group.

\begin{abstract}
Methods: A preliminary, randomized, controlled trial was conducted to investigate whether remote ischemic preconditioning in cyanosed neonates undergoing cardiac surgery confers protection against cardiopulmonary bypass. Two groups of neonates undergoing cardiac surgery were recruited for the present study: patients with transposition of the great arteries undergoing the arterial switch procedure and patients with hypoplastic left heart syndrome undergoing the Norwood procedure. The subjects were randomized to the remote ischemic preconditioning or sham control groups. Remote ischemic preconditioning was induced by four 5-minute cycles of lower limb ischemia and reperfusion using a blood pressure cuff. Troponin I and the biomarkers for renal and cerebral injury were measured pre- and postoperatively.
\end{abstract}

Results: A total of 39 neonates were recruited-20 with transposition of the great arteries and 19 with hypoplastic left heart syndrome. Of the 39 neonates, 20 were randomized to remote ischemic preconditioning and 19 to the sham control group. The baseline demographics appeared similar between the randomized groups. The cardiopulmonary bypass and crossclamp times were not significantly different between the 2 groups. The troponin I levels were not significantly different at 6 hours after cardiopulmonary bypass nor were the postoperative inotrope requirements. Markers of renal (neutrophil gelatinase-associated lipocalin) and cerebral injury (S100b, neuron-specific enolase) were not significantly different between the 2 groups.

Conclusions: Our data suggest that remote ischemic preconditioning in hypoxic neonates undergoing cardiopulmonary bypass surgery does not provide myocardial, renal, or neuronal protection. Additional studies are needed to examine the relationships among developmental age, hypoxia, and the molecular mechanisms of ischemic preconditioning. (J Thorac Cardiovasc Surg 2013;146:1334-40)

Earn CME credits at

http://cme.ctsnetjournals.org

Ischemia-reperfusion (IR) injury and cardiopulmonary bypass (CPB) during cardiac surgery are associated with marked metabolic stress involving a systemic inflammatory

\footnotetext{
From the Department of Cardiology, ${ }^{a}$ Royal Children's Hospital, Melbourne, Victo-

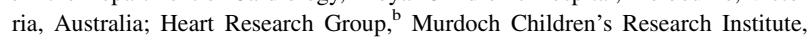
Parkville, Victoria, Australia; Department of Paediatrics, ${ }^{c}$ University of Melbourne, Melbourne, Victoria, Australia; Clinical Epidemiology and Biostatistics Unit, ${ }^{\mathrm{d}}$ Murdoch Children's Research Institute, Parkville, Victoria, Australia; National Perinatal and Epidemiology Unit, ${ }^{\mathrm{e}}$ University of Oxford, Oxford, United Kingdom; Paediatric Critical Care, ${ }^{\mathrm{f}}$ Texas Children's Hospital, Houston, Tex; Department of Cardiology, ${ }^{\mathrm{g}}$ Texas Children's Hospital, Houston, Tex; Department of Anaesthesia, ${ }^{\text {h }}$ Royal Children's Hospital, Melbourne, Victoria, Australia; and Cardiac Surgery Unit, ${ }^{i}$ Royal Children's Hospital, Melbourne, Victoria, Australia.

Dr Jones was supported by a National Heart Foundation Postgraduate Scholarship; Dr Cheung is a Career Development Fellow of the National Heart Foundation of Australia; Dr d'Udekem is a Career Development Fellow of the National Heart Foundation of Australia (grant CR 10M 5339); Dr Sheeran was supported by an National
}

response and significant myocardial and pulmonary endothelial dysfunction. ${ }^{1}$ These events contribute to postoperative morbidity and mortality in any patient after cardiac surgery but are particularly prominent in infants undergoing repair of congenital lesions. ${ }^{2}$

Although "off-pump" surgical strategies to avoid or minimize exposure to IR injury and CPB have been developed to treat ischemic heart disease, $\mathrm{CPB}$ remains a necessary

Health and Medical Research Council postdoctoral training award. This study was supported by a research grant from Manchester Unity, HeartKids Australia, and the Sylvia Viertel Charitable Foundation. The Murdoch Childrens Research Institute is supported by the Victorian Government's Operational Infrastructure Support Program.

Disclosures: Authors have nothing to disclose with regard to commercial support. Received for publication Oct 5, 2012; revisions received Dec 19, 2012; accepted for publication Jan 11, 2013; available ahead of print Feb 18, 2013.

Address for reprints: Michael M. H. Cheung, MB, ChB, MD, Department of Cardiology, Royal Children's Hospital, Flemington Rd, Parkville, Victoria 3052, Australia (E-mail: michael.cheung@rch.org.au).

$0022-5223 / \$ 36.00$

Copyright (C) 2013 by The American Association for Thoracic Surgery

http://dx.doi.org/10.1016/j.jtcvs.2013.01.003 


\section{Abbreviations and Acronyms \\ $\mathrm{CPB}=$ cardiopulmonary bypass \\ HLHS $=$ hypoplastic left heart syndrome \\ IPC $=$ ischemic preconditioning \\ IR $=$ ischemia-reperfusion \\ NGAL $=$ neutrophil gelatinase-associated lipocalin \\ NSE $=$ neuron-specific enolase \\ RIPC $=$ remote ischemic preconditioning \\ TGA $=$ transposition of the great arteries}

aspect of complex surgery for congenital heart disease. Thus, significant interest remains in therapies that can minimize organ injury in this setting. Extensive work has examined the innate protective mechanism of ischemic preconditioning (IPC), initially described in $1986 .{ }^{3}$ The delivery of a direct IPC stimulus to the organ of interest has been demonstrated to reduce IR injury in the heart and other organs across a wide range of studied species. However, it was not until 1993 that the paradigm of a remote stimulus to induce protection of a distant organ was first described. ${ }^{4}$ In 2006, we reported our findings of the first randomized control trial in humans of the protective effect of remote IPC (RIPC) in children undergoing cardiac surgery for congenital heart defects. ${ }^{5}$ In that study, we demonstrated myocardial protection with lower levels of postoperative troponin I release and also improved ventricular function in those children receiving RIPC.

Because that previous study was limited by patient heterogeneity owing to the diverse congenital heart defects and a wide age range, the aim of the present randomized controlled trial was to examine RIPC in a more homogeneous group of children undergoing cardiac surgery. Neonates with either transposition of the great arteries (TGA) or hypoplastic left heart syndrome (HLHS) were selected because the arterial switch operation and the stage I Norwood procedure are lengthy, but relatively uniform, surgical procedures performed at a point of organ immaturity when the reduction of organ injury could confer its greatest clinical benefit.

\section{METHODS}

Neonatal patients ( $<28$ days old) undergoing the arterial switch procedure for TGA, or the Norwood stage 1 procedure with a modified BlalockTaussig shunt for HLHS at the Royal Children's Hospital (Melbourne, Victoria, Australia) were identified. Patients with chromosomal defects, associated congenital lung malformations, and hematologic disorders were excluded. Also, children outside the neonatal period at surgical repair were excluded. Patients requiring intracardiac surgery involving direct trauma to the ventricular myocardium, such as ventricular septal defect closure or a right ventricle to pulmonary artery conduit, were excluded to avoid confounding the assessment of myocardial injury by measurement of the plasma levels of troponin I.

The patients' parents or guardians provided informed consent before enrollment. After recruitment, the subjects were randomized to either the
RIPC or the sham control group. The randomization schedule was generated by the Clinical Biostatistics and Epidemiology Unit (Murdoch Children's Research Institute, Melbourne, Victoria, Australia). Randomization was by block and stratified by the 2 diagnostic groups (HLHS and TGA) with a 1:1 ratio. Only the researchers were aware of the randomization, and the staff providing clinical care was unaware of the randomization and group allocations.

The Royal Children's Hospital human research ethics committee approved the study protocol. The study was registered with the Australia New Zealand Clinical Trials Registry (ACTRN12607000004460).

\section{Anesthesia and CPB Protocol}

The anesthetic protocol was as follows. For infants with intravenous access, induction was with intravenous fentanyl (10-50 $\mu \mathrm{g} / \mathrm{kg})$ and pancuronium $(0.2 \mathrm{mg} / \mathrm{kg})$. For those without intravenous access, induction was with inhalational agents (nitric oxide or sevoflurane $3 \%$ ) and topical lidocaine $(\leq 4 \mathrm{mg} / \mathrm{kg})$ to the vocal cords before intubation. All subjects received methylprednisolone $(25 \mathrm{mg} / \mathrm{kg}$ ) and cephazolin $(50 \mathrm{mg} / \mathrm{kg}$ and then $20 \mathrm{mg} / \mathrm{kg}$ every 3 hours). Aprotonin (50,000 kallikrein inhibition units $/ \mathrm{kg}$ loading dose and then 10,000 kallikrein inhibition units $/ \mathrm{kg} / \mathrm{hr}$ plus 10,000 kallikrein inhibition units/100 mL pump prime) was used during the initial period of the study before it became unavailable; thereafter, tranexamic acid was used $(100 \mathrm{mg} / \mathrm{kg}$ loading dose and then $10 \mathrm{mg} / \mathrm{kg} / \mathrm{hr}$ ).

Anesthesia was maintained with fentanyl boluses of 10 to $20 \mu \mathrm{g} / \mathrm{kg}$ as required to cover the incision, sternotomy, and post-CPB phases, morphine ( 0.2 to $0.5 \mathrm{mg} / \mathrm{kg}$ in the pump prime) and pancuronium $(0.1-0.2 \mathrm{mg} / \mathrm{kg}$ and $0.2 \mathrm{mg} / 100 \mathrm{~mL}$ of pump prime). Isoflurane ( $2 \%$ ) was titrated as required, including during CPB.

CPB was established by direct superior vena cava, inferior vena cava, and ascending aortic cannulation. Our standard circuit was primed using plasmalyte 148 with added heparin, calcium, bicarbonate, and 20\% albumin. Fresh packed red blood cells less than 3 days old that were leukocyte depleted and irradiated were added, followed by hemofiltration of the prime solution to a reservoir volume of $250 \mathrm{~mL}$.

In our unit, all patients with HLHS undergoing the Norwood procedure were cooled to $26^{\circ} \mathrm{C}$ during $\mathrm{CPB}$, with selective cerebral low flow perfusion used. The adequacy of cerebral oxygenation was assessed using near infrared spectroscopy. Patients with TGA undergoing arterial switch operation were cooled to $32^{\circ} \mathrm{C}$ during $\mathrm{CPB}$.

Modified ultrafiltration was performed according to standard bypass protocols at the Royal Children's Hospital. The duration of CPB and aortic crossclamp time and the intraoperative opiate dose were recorded.

\section{RIPC Protocol}

After induction of general anesthesia and insertion of arterial monitoring and central venous lines, the RIPC protocol was performed. Preconditioning was induced by four 5-minute cycles of lower limb ischemia and 5 minutes of reperfusion using a blood pressure cuff inflated around the thigh to a pressure $15 \mathrm{~mm} \mathrm{Hg}$ greater than the monitored systolic arterial pressure. The control patients underwent sham placement of the blood pressure cuff around the thigh without inflation. The clinicians caring for the patients were screened from the preconditioning procedure.

\section{Outcome Measures}

The primary outcome measure was the troponin I level at 6 hours after $\mathrm{CPB}$ as a marker of myocardial injury. The secondary outcome measures were the troponin levels at 3,12 , and 24 hours after CPB and the neutrophil gelatinase-associated lipocalin (NGAL), neuron-specific enolase (NSE), and S100B levels at 3, 6, 12, and 24 hours after CPB. The cardiovascular status, lung function, and postoperative inotrope requirements were also assessed at 3, 6, 12, and 24 hours after CPB. 


\section{Measurements}

All blood samples were collected from the arterial monitoring catheter. The samples were collected at baseline immediately before surgery and again at 3,6,12, and 24 hours after surgery. The samples were collected, centrifuged, and frozen at $-70^{\circ} \mathrm{C}$ for subsequent analysis. The analyses of the samples were performed in triplicate and blinded to treatment group. The plasma troponin I levels were measured as a marker of myocardial injury using the Abbott AxSYM Troponin-I immunoassay (Abbott Laboratories, Abbott Park, Ill). Assays of the markers of cerebral injury (S100b, NSE) and renal injury (NGAL) were also performed using sandwich enzyme-linked immunosorbent assay microtiter plate-based spectrophotometric procedures. For NGAL, previously described methods were used, ${ }^{6}$ with polyclonal human NGAL and avidin-conjugated horseradish peroxidase antibodies (catalog no. KA0043 V.03; Abnova, Taipei City, Taiwan). S100b was similarly determined using monoclonal antibody for human S100b recognition (Abnova, catalog no. KA0037). Human NSE ( $\gamma$-subunit recognition) was quantitatively determined for the biotinylated antibodyNSE-chromogen complex using the general method of Paus and Nustad ${ }^{7}$ (catalog no. 0050; Alpha Diagnostic International, San Antonio, Tex). The total protein levels were determined using the bicinchoninic acid protein assay (Sigma-Aldrich, St Louis, Mo).

\section{Postoperative Assessment}

The patients' postoperative recovery in the intensive care unit was assessed at the same points as for blood sampling $(3,6,12$, and 24 hours after CPB) and included documentation of inotropic support, ventilatory support, urine output, and arterial lactate levels. The postoperative opiate dose, total duration of ventilation, and length of intensive care unit stay were also documented. The oxygenation index and alveolar-arterial gradient were calculated from the ventilatory parameters: (oxygenation index $=$ fraction of inspired oxygen $\times$ mean arterial pressure/arterial partial pressure of oxygen; alveolar-arterial gradient $=$ alveolar partial pressure in oxygen - arterial partial pressure in oxygen). The vasoactive inotrope score was calculated according to the previously described formula ${ }^{8}$ : vasoactive inotrope score $=$ dopamine dose $(\mu \mathrm{g} / \mathrm{kg} /$ $\min )+$ dobutamine dose $(\mu \mathrm{g} / \mathrm{kg} / \mathrm{min})+100 \times$ adrenaline dose $(\mu \mathrm{g} / \mathrm{kg} /$ $\min )+100 \times$ noradrenaline dose $(\mu \mathrm{g} / \mathrm{kg} / \mathrm{min})+10 \times$ milrinone dose $(\mu \mathrm{g} / \mathrm{kg} / \mathrm{min})$. The total opiate requirements were determined as the sum of the intraoperative and postoperative opioid doses. The doses of fentanyl were converted into morphine equivalents per kilogram body weight using a relative potency of fentanyl to morphine of 100:1.

\section{Sample Size and Statistical Analysis}

A paucity of data was available for this patient population to enable an accurate sample size calculation. The intention was to use the data from the present preliminary study to determine the future sample size calculations.

The difference between the treatment and control groups was estimated using linear regression analysis, with adjustment for the stratification factor (TGA or HLHS).

In each of the 2 diagnostic groups, the difference between the treatment and control group was estimated using $t$ tests.

Differences between the treatment groups were investigated at 3, 6, 12, and 24 hours after surgery. For the variables measured at several points after surgery, a summary measure, the area under the curve, was also calculated, as an alternative outcome measure.

Statistical analysis was performed using Stata, version 11 (StataCorp 2011, College Station, Tex).

\section{RESULTS}

\section{Neonates}

A total of 39 neonates were recruited from January 2008 to January 2011, 20 with TGA and 19 with HLHS. In the
TABLE 1. Preoperative characteristics of treatment and sham control groups

\begin{tabular}{lcc}
\hline Characteristic & Treatment group $(\mathbf{n}=\mathbf{2 0})$ & Control group $(\mathbf{n}=\mathbf{1 9})$ \\
\hline Age at surgery $(\mathrm{d})$ & $8.1 \pm 5.2$ & $5.5 \pm 4.2$ \\
Weight $(\mathrm{kg})$ & $3.5 \pm 0.577$ & $3.4 \pm 0.449$ \\
BSA $\left(\mathrm{m}^{2}\right)$ & $0.21 \pm 0.022$ & $0.21 \pm 0.016$ \\
Troponin I $(\mu \mathrm{g} / \mathrm{L})$ & $0.061 \pm 0.081$ & $0.041 \pm 0.035$ \\
S100b $(\mathrm{pg} / \mathrm{mL})$ & $203.0 \pm 48.4$ & $226.2 \pm 117.3$ \\
NSE $(\mu \mathrm{g} / \mathrm{L})$ & $149.8 \pm 75.5$ & $96.7 \pm 49.5$ \\
NGAL $(\mathrm{ng} / \mathrm{mL})$ & $59.2 \pm 38.6$ & $46.1 \pm 38.3$ \\
TGA & $11(55)$ & $9(51)$ \\
HLHS & $9(45)$ & $10(49)$ \\
\hline
\end{tabular}

Data presented as mean \pm standard deviation or $\mathrm{n}(\%) . B S A$, Body surface area; $N S E$, neuron-specific enolase; $N G A L$, neutrophil gelatinase-associated lipocalin; $T G A$, transposition of great arteries; $H L H S$, hypoplastic left heart syndrome.

TGA group, 11 were randomized to RIPC and 9 to the sham control group, and in the HLHS group, 9 were randomized to RIPC and 10 to the sham control group. All subjects received the intervention according to their allocation. The preoperative characteristics between the RIPC and sham groups were similar (Table 1). No local adverse events or changes to cardiovascular stability occurred in relationship to the preconditioning stimulus in either group.

The mean age at surgery was $8.1 \pm 5.2$ days in the RIPC group and $5.5 \pm 4.2$ days in the control group. The duration of CPB and the crossclamp time appeared similar between the 2 groups (Table 2). The mean interval from the completion of the RIPC protocol to the beginning of CPB was 80 minutes (range, 50-120 minutes). Two subjects received aprotinin during surgery, with the rest receiving tranexamic acid.

No deaths occurred in the perioperative period (30 days) in either group, and all subjects were successfully discharged from the hospital.

\section{Myocardial Function and Injury}

In the total cohort, the mean troponin level at 6 hours after CPB was $11.4 \mu \mathrm{g} / \mathrm{L}$ in the RIPC group and $10.6 \mu \mathrm{g} / \mathrm{L}$ in the control group, with no differences evident (Table 3 and Figure 1). Similarly, no evidence was found of a difference at the other measurement points analyzed nor with a 24-hour area under the curve analysis, although the confidence intervals were wide. Other indirect markers of myocardial function and cardiac output, including inotrope scores, urine output, and serum lactate levels, were not statistically significantly different between the 2 groups (Table 4).

\section{Lung Function}

No evidence was found of a difference in the oxygenation index or alveolar-arterial oxygen difference between the 2 groups (Table 4). No statistically significant difference was found in the duration of mechanical ventilation between the 2 groups (HLHS: RIPC, $126 \pm 31$ hours, vs 
TABLE 2. Intraoperative data

\begin{tabular}{|c|c|c|c|c|c|c|}
\hline Variable & Treatment group mean & Control group mean & $\begin{array}{c}\text { Mean difference } \\
\text { (control minus treatment)* }\end{array}$ & $\begin{array}{c}\mathbf{9 5} \% \text { CI for } \\
\text { mean difference* }\end{array}$ & $P$ value & Patients (n) \\
\hline \multicolumn{7}{|l|}{ Total cohort } \\
\hline CPB time $(\min )$ & 173.9 & 185.4 & 12.0 & $-12.5,36.6$ & .33 & 39 \\
\hline Crossclamp time (min) & 95.3 & 94.4 & 1.7 & $-13.5,16.9$ & .82 & 39 \\
\hline \multicolumn{7}{|l|}{ TGA } \\
\hline CPB time (min) & 172.6 & 194.1 & 21.5 & $-1.7,44.7$ & .07 & 20 \\
\hline Crossclamp time (min) & 109.3 & 114.4 & 5.2 & $-7.4,17.7$ & .40 & 20 \\
\hline \multicolumn{7}{|l|}{ HLHS } \\
\hline CPB time (min) & 175.4 & 177.6 & 2.2 & $-44.4,48.7$ & .92 & 19 \\
\hline Crossclamp time (min) & 78.3 & 76.4 & -1.9 & $-31.8,28.0$ & .89 & 19 \\
\hline
\end{tabular}

$C I$, Confidence interval; $C P B$, cardiopulmonary bypass; $T G A$, transposition of great arteries; $H L H S$, hypoplastic left heart syndrome. *Adjusted for stratification factor (TGA vs HLHS).

control, $147 \pm 94$ hours; $P=.52$; TGA: RIPC, $51 \pm 23$ hours, vs control, $66 \pm 56$ hours; $P=.44$ ).

\section{Other Markers of Renal and Cerebral Injury}

No evidence was found of a difference in the serum levels of the markers of renal injury (NGAL) or cerebral injury (NSE and S100b) between the 2 groups (Table 4).

Peritoneal dialysis was needed in $35 \%$ of the treatment group and $42 \%$ of the control group $(P=.65$, chi-square test). No significant neurologic events were reported in either group; however, formal neurologic assessments were not performed.

\section{Intraoperative and Postoperative Opiates}

No evidence was found of a difference in the intraoperative and postoperative opiate dosage (quantified in morphine equivalents) between the 2 groups. Intraoperatively, the dosage for the control group was a mean of $7.36 \pm 2.95 \mathrm{mg} / \mathrm{kg}$, and for the RIPC group, it was $8.19 \pm 3.57 \mathrm{mg} / \mathrm{kg}(P=.44)$. Postoperatively, the dosage for the control group was a mean of $1.64 \pm 1.03 \mathrm{mg} / \mathrm{kg}$, and for the RIPC group, it was $1.8 \pm 1.1 \mathrm{mg} / \mathrm{kg}$ $(P=.65)$. No correlation was found between the intraoperative opiate dose and the postoperative troponin I levels.

\section{DISCUSSION}

Since the first clinical human study demonstrating the beneficial effects of RIPC on myocardial protection in children

TABLE 3. Primary outcome (all patients, adjusted for diagnosis group)

\begin{tabular}{lcc}
\hline & \multicolumn{2}{c}{ Troponin at $\mathbf{6 ~ h r}(\mu \mathrm{g} / \mathbf{L})$} \\
\cline { 2 - 3 } \multicolumn{1}{c}{ Variable } & Unadjusted & $\begin{array}{c}\text { Adjusted for } \\
\text { preoperative troponin }\end{array}$ \\
\hline $\begin{array}{l}\text { Mean difference (control minus } \\
\text { treatment) }\end{array}$ & -0.29 & -0.18 \\
$95 \%$ CI for mean difference & $-3.3,2.7$ & $-3.3,2.9$ \\
$P$ value & .85 & .91 \\
Patients (n) & 38 & 38 \\
\hline
\end{tabular}

CI, Confidence interval. undergoing cardiac surgery for congenital heart disease, ${ }^{5}$ numerous human studies have applied this technique, although predominantly in adults. In a large randomized trial, RIPC was shown to reduce myocardial injury in patients undergoing coronary artery bypass grafting and receiving cold blood cardioplegia, with a $42 \%$ reduction in troponin release (AUC 72 hours mean difference, $13.37 \mu \mathrm{g} / \mathrm{L} .72$ hours; $95 \%$ confidence interval, $2.41-24.33, P=.019) .{ }^{10}$ Additionally, a systematic review and meta-analysis of pooled data from 184 subjects demonstrated a statistically significant benefit of RIPC compared with a control group for a reduction in the biomarkers of myocardial injury. ${ }^{11}$

A paucity of studies, however, of children with congenital heart disease is available. One study of 60 infants undergoing surgical repair of ventricular septal defects ${ }^{12}$ also demonstrated myocardial and pulmonary protection as a result of RIPC administered at 24 hours and 1 hour before $\mathrm{CPB}$. The subjects randomized to preconditioning had lower troponin levels at 4 hours after CPB (RIPC, $2.1 \pm 0.32 \mu \mathrm{g} / \mathrm{L}$ vs control, $2.41 \pm 0.32 \mu \mathrm{g} / \mathrm{L} ; P<.05)$. These children were older than our study population, with

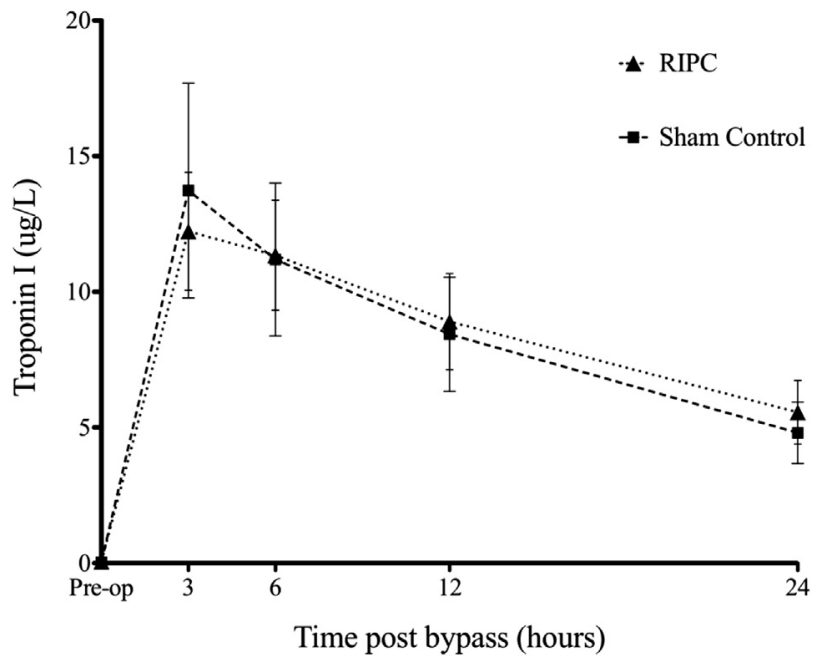

FIGURE 1. Troponin I levels at baseline and 3, 6, 12, and 24 hours after cardiopulmonary bypass. RIPC, Remote ischemic preconditioning. 
TABLE 4. Secondary outcomes

\begin{tabular}{|c|c|c|c|c|c|}
\hline Variable & Treatment group mean & Control group mean & $\begin{array}{c}\text { Mean difference } \\
\text { (control minus treatment)* }\end{array}$ & $\begin{array}{c}95 \% \text { CI for } \\
\text { mean difference* }\end{array}$ & Patients (n) \\
\hline \multicolumn{6}{|l|}{ Troponin $(\mu \mathrm{g} / \mathrm{L})$} \\
\hline At $3 \mathrm{~h}$ & 12.2 & 13.7 & 1.9 & $-1.8,5.6$ & 38 \\
\hline At $12 \mathrm{~h}$ & 8.9 & 8.4 & -0.2 & $-2.5,2.2$ & 39 \\
\hline At $24 \mathrm{~h}$ & 5.6 & 4.8 & -0.4 & $-1.8,0.9$ & 37 \\
\hline \multicolumn{6}{|l|}{ Urine output $(\mathrm{mL} / \mathrm{kg} / \mathrm{h})$} \\
\hline At $3 \mathrm{~h}$ & 2.1 & 2.2 & 0.1 & $-1.3,1.5$ & 39 \\
\hline At $6 \mathrm{~h}$ & 1.2 & 1.5 & 0.4 & $-0.5,1.3$ & 39 \\
\hline At $12 \mathrm{~h}$ & 1.0 & 1.1 & 0.1 & $-0.7,0.9$ & 39 \\
\hline Urine output $(\mathrm{mL}) 24 \mathrm{~h}$ & 5.8 & 5.2 & -0.4 & $-4.2,3.3$ & 39 \\
\hline \multicolumn{6}{|l|}{ Lactate } \\
\hline At $3 \mathrm{~h}$ & 3.0 & 3.1 & 0.1 & $-0.9,1.0$ & 38 \\
\hline At $6 \mathrm{~h}$ & 2.4 & 2.7 & 0.2 & $-0.8,1.1$ & 39 \\
\hline At $12 \mathrm{~h}$ & 2.3 & 2.6 & 0.2 & $-0.7,1.1$ & 39 \\
\hline At $24 \mathrm{~h}$ & 1.8 & 2.2 & 0.3 & $-0.1,0.7$ & 39 \\
\hline \multicolumn{6}{|l|}{ Inotrope score } \\
\hline At $3 \mathrm{~h}$ & 6.2 & 9.0 & 2.5 & $-1.4,6.5$ & 39 \\
\hline At $6 \mathrm{~h}$ & 6.8 & 9.4 & 2.6 & $-0.7,5.9$ & 39 \\
\hline At $12 \mathrm{~h}$ & 7.6 & 9.7 & 2.2 & $-1.5,5.9$ & 39 \\
\hline At $24 \mathrm{~h}$ & 6.8 & 8.9 & 2.2 & $-0.9,5.4$ & 39 \\
\hline \multicolumn{6}{|l|}{ Alveolar-arterial difference } \\
\hline At $3 \mathrm{~h}$ & 169.8 & 150.0 & -21.6 & $-83.5,40.4$ & 39 \\
\hline At $6 \mathrm{~h}$ & 151.7 & 146.0 & -5.8 & $-58.4,46.7$ & 39 \\
\hline At $12 \mathrm{~h}$ & 127.5 & 109.8 & -16.9 & $-61.1,27.3$ & 39 \\
\hline At $24 \mathrm{~h}$ & 98.0 & 92.1 & -5.7 & $-47.2,35.7$ & 39 \\
\hline \multicolumn{6}{|l|}{ OI } \\
\hline At $3 \mathrm{~h}$ & 7.1 & 8.6 & 1.0 & $-2.5,4.4$ & 39 \\
\hline At $6 \mathrm{~h}$ & 6.1 & 6.9 & 0.5 & $-1.7,2.7$ & 39 \\
\hline At $12 \mathrm{~h}$ & 5.7 & 5.3 & -0.7 & $-2.5,1.1$ & 39 \\
\hline At $24 \mathrm{~h}$ & 4.7 & 4.8 & -0.2 & $-1.5,1.2$ & 39 \\
\hline $\mathrm{S} 100 \mathrm{~b}(\mathrm{pg} / \mathrm{mL})$ at $24 \mathrm{~h}$ & 173.3 & 132.3 & -37.8 & $-111.2,35.7$ & 30 \\
\hline $\mathrm{NSE}(\mu \mathrm{g} / \mathrm{L})$ at $24 \mathrm{~h}$ & 107.2 & 111.0 & 4.2 & $-31.6,40.1$ & 30 \\
\hline \multicolumn{6}{|l|}{ NGAL (ng/mL) } \\
\hline At $3 \mathrm{~h}$ & 57.7 & 59.0 & -0.8 & $-22.6,21.0$ & 29 \\
\hline At $6 \mathrm{~h}$ & 56.8 & 54.3 & -6.4 & $-25.9,13.1$ & 27 \\
\hline At $12 \mathrm{~h}$ & 63.2 & 62.3 & -2.5 & $-22.6,17.5$ & 34 \\
\hline At $24 \mathrm{~h}$ & 77.5 & 60.0 & -19.4 & $-47.8,8.9$ & 29 \\
\hline
\end{tabular}

CI, Confidence interval; $O I$, oxygenation index; NSE, neuron-specific enolase; $N G A L$, neutrophil gelatinase-associated lipocalin; $T G A$, transposition of greater arteries; $H L H S$, hypoplastic left heart syndrome. *Adjusted for stratification factor (TGA or HLHS).

an age range of 81 to 270 days. Additionally, all children in that study had normal oxygen saturation at rest. Pavione and colleagues ${ }^{13}$ evaluated the late effects of RIPC in children undergoing cardiac surgery by administering the RIPC stimulus 24 hours before CPB. These children were also older than our study population (age range, 1.4-21.1 months) and included a heterogeneous group of cardiac diagnoses. Although no significant difference was found in the troponin levels, inflammatory markers, or clinical outcomes between the RIPC and control groups, the N-terminal pro-B-type natriuretic peptide levels were lower in the RIPC group. The investigators suggested that a myocardial protective effect might have been present that was not clinically significant. That study, however, had a small sample size (22 children in total) and might have been underpowered to detect a difference in the troponin levels and clinical parameters.

\section{Organ Injury}

In common with many other studies, we chose troponin I as the primary marker of myocardial injury. No evidence was seen of a difference between the RIPC and control groups in troponin I levels. Nor was evidence found of differences in the indexes of systemic perfusion or inotrope requirement, suggesting no difference in the degree of myocardial dysfunction between the groups. Importantly, no evidence was found that the RIPC stimulus was harmful to myocardial function.

There are several potential reasons why we were unable to detect any difference in myocardial injury in our 
population. These included the timing of the RIPC stimulus relative to birth, organ immaturity, and tissue hypoxia. It has previously been reported that the infant heart exhibits high levels of endogenous methionine-enkephalin, and. in particular, an inverse correlation exists between the arterial oxygen saturation and myocardial methionine-enkephalin content in children undergoing tetralogy of Fallot repair. ${ }^{14}$ Preconditioning has been demonstrated to be protective in mature myocardium in both animal and human studies; however, doubts have been raised regarding the efficacy of preconditioning on the newborn and immature myocardium, with conflicting data from animal studies. Bin and colleagues ${ }^{15}$ showed no protection against IR injury with preconditioning in a juvenile rabbit model (aged 14-21 days). In a rat model, Awad and colleagues ${ }^{16}$ demonstrated that protection against IR injury was provided by preconditioning after 7 days of age but not before. This finding conflicts with the data from Liu and colleagues, who demonstrated a protective effect in immature rabbit hearts (aged 4-7 days). ${ }^{17}$ Baker and colleagues ${ }^{18}$ also showed that a single cycle of 5 minutes of direct ischemia and 10 minutes of reperfusion conferred protection from global ischemia in the normoxic immature rabbit heart (aged 7-10 days). These discrepancies in findings could be ascribed to the different animal species, models, endogenous opioid peptide levels, and variable rates of intracellular signal transduction system maturation.

Chronic myocardial hypoxia has been demonstrated in mature animal models to improve tolerance to reperfusion-reperfusion injury. ${ }^{19}$ Furthermore, Tajima and colleagues $^{20}$ demonstrated that chronic hypoxia increased myocardial tolerance to ischemia in 3-week-old rats and that acute IPC increased this tolerance further. However, the molecular mechanisms responsible for the myocardial protection conferred by chronic hypoxia remain poorly understood. Possible contributory mechanisms for this resistance include elevated levels of hypoxia-inducible factor- $1 \alpha,{ }^{21}$ and alterations in nitric oxide synthase.

There is some suggestion from animal data that chronic hypoxia also confers protection in immature myocardium; however, the cumulative effect of chronic hypoxia and preconditioning has been questioned. In the study by Baker and colleagues, ${ }^{18}$ a separate group of animals were raised from birth in hypoxic conditions and studied at a similar age (7-10 days). The same protocol of IPC in these hypoxic animals had no effect on resistance to an ischemic insult. Increasing the number of cycles of IPC also did not have any beneficial effect. The hearts of the hypoxic control animals tolerated global ischemia better than did the normoxic controls, suggesting that chronic hypoxia in itself conferred protection in these immature hearts.

The possibility of potentially detrimental effects of IPC on ventricular function after global IR injury has been raised in a recent animal study. ${ }^{22}$ However, our data did not support these findings and did not show any difference in the clinical course or surrogate markers of ventricular function. It must be highlighted, however, that our patients were all cyanosed.

The ability of the hypoxic and immature myocardium to withstand ischemia is of great importance, because many children with complex cyanotic heart malformations undergo cardiac surgery in the neonatal period. The findings from animal studies have suggested that chronically hypoxic immature hearts could be protected by adaptation to hypoxia; however, no additional protection is provided by IPC. It is possible that IPC signaling pathways might not be fully mature in the developing neonate. Additional studies are clearly needed to examine the relationship among myocardial maturity, hypoxia, and IPC.

\section{Injury to Other Organs}

No evidence was found of a difference between the markers of either neuronal or renal injury between the RIPC and control groups. This might have been because of a lack of effect or because subtle injuries were not able to be detected using the assays. Because ours was an acute study, the potential role in protection against long-term neuropsychological sequelae was not assessed.

Animal studies of cerebral injury have demonstrated the protective effect of preconditioning against injury from hypothermic circulatory arrest. ${ }^{23,24}$ Jensen and colleagues $^{23}$ used a surviving animal model and demonstrated protection according to biochemical, functional, and histologic findings. However, conflicting data remain regarding the optimal time of preconditioning for cerebral protection, with our own experimental study of rats demonstrating a lack of cerebral protection. ${ }^{24,25}$ The role of preconditioning in cerebral protection of the immature brain is unknown, and no other human studies to date have examined the effects of RIPC on neurologic injury after cardiac surgery.

Acute kidney injury after cardiac surgery in children is common, with some studies reporting that up to $11.5 \%$ of children require dialysis. ${ }^{26}$ Some evidence has shown that RIPC might protect renal function from IR injury. ${ }^{27}$ However, a recent randomized controlled study of RIPC $^{28}$ of 105 children undergoing cardiac surgery was unable to demonstrate renal protection. A difference was found in the incidence of acute kidney injury $(41 \%$ in RIPC group and $67 \%$ in the control group; $P=.04$ ) in children older than 12 months that might also reflect a maturational response to preconditioning. That study supports our findings and perhaps also reflects the relatively low sensitivity and specificity of the available biomarkers.

\section{Study Limitations}

The lack of a statistically significant difference between the 2 groups might be primarily attributed to an insufficient sample size and the study being underpowered. 
However, similar size studies of other patient populations, including children, have demonstrated clinical effects. ${ }^{5,12}$ Additionally, no evidence was found of a clinically detectable difference between the 2 groups.

The preconditioning properties of inhalational anesthetics and opiates have been well described; however, these factors and other potentially confounding variables were minimized by using standardized anesthetic and perfusion protocols.

\section{CONCLUSIONS}

Our data suggest that IPC in hypoxic neonates does not provide cardioprotection, nor protection against renal or cerebral injury in newborns undergoing cardiac surgery for cyanotic heart disease. It remains unclear whether the use of blood cardioplegia, opiates, and the intrinsic organ properties unique to these neonatal patients might have masked or negated any additional protective benefit of RIPC. Because it would clearly be desirable to maximize organ protection in this vulnerable group of patients and minimize long-term morbidity, additional studies are required to examine the relationship among myocardial development, age, hypoxia, and IPC.

\section{References}

1. Levy JH, Tanaka KA. Inflammatory response to cardiopulmonary bypass. Ann Thorac Surg. 2003;75:S715-20.

2. Ungerleider RM, Shen I. Optimizing response of the neonate and infant to cardiopulmonary bypass. Semin Thorac Cardiovasc Surg Pediatr Card Surg Аппи. 2003;6:140-6.

3. Murry CE, Jennings RB, Reimer KA. Preconditioning with ischemia: a delay of lethal cell injury in ischemic myocardium. Circulation. 1986;74: 1124-36.

4. Przyklenk K, Bauer B, Ovize M, Kloner RA, Whittaker P. Regional ischemic "preconditioning" protects remote virgin myocardium from subsequent sustained coronary occlusion. Circulation. 1993;87:893-9.

5. Cheung MM, Kharbanda RK, Konstantinov IE, Shimizu M, Frndova H, Li J, et al. Randomized controlled trial of the effects of remote ischemic preconditioning on children undergoing cardiac surgery: first clinical application in humans. J Am Coll Cardiol. 2006;47:2277-82.

6. Mishra J, Dent C, Tarabishi R, Mitsnefes MM, Ma Q, Kelly C, et al. Neutrophil gelatinase-associated lipocalin (NGAL) as a biomarker for acute renal injury after cardiac surgery. Lancet. 2005;365:1231-8.

7. Paus E, Nustad K. Immunoradiometric assay for alpha gamma- and gamma gamma-enolase (neuron-specific enolase), with use of monoclonal antibodies and magnetizable polymer particles. Clin Chem. 1989;35:2034-8.

8. Gaies M, Gurney J, Yen A, Napoli ML, Gajarski RJ, Ohye RG, et al. Vasoactiveinotropic score as a predictor of morbidity and mortality in infants after cardiopulmonary bypass. Pediatr Crit Care Med. 2010;11:234-8.

9. Heard C, Fletcher J. Sedation and analgesia. In: Fuhrman B, Zimmerman J, eds. Pediatric critical care. Philadelphia: Mosby; 2006:1748-79.
10. Venugopal V, Hausenloy DJ, Ludman A, Di Salvo C, Kolvekar S, Yap J, et al. Remote ischaemic preconditioning reduces myocardial injury in patients undergoing cardiac surgery with cold blood cardioplegia: a randomised controlled trial. Heart. 2009;95:1567-71.

11. Takagi H, Manabe H, Kawai N, Goto SN, Umemoto T. Review and meta-analysis of randomized controlled clinical trials of remote ischemic preconditioning in cardiovascular surgery. Am J Cardiol. 2008;102:1487-8.

12. Wenwu Z, Debing Z, Renwei C, Jian L, Guangxian Y, Pingbo L, et al. Limb ischemic preconditioning reduces heart and lung injury after an open heart operation in infants. Pediatr Cardiol. 2010;31:22-9.

13. Pavione MA, Carmona F, de Castro M, Carlotti AP. Late remote ischemic preconditioning in children undergoing cardiopulmonary bypass: a randomized controlled trial. J Thorac Cardiovasc Surg. 2012;144:178-83.

14. van den Brink OW, Cochrane AD, Rosenfeldt FL, Penny DJ, Pepe S. Increased myocardial methionine-enkephalin with reduced arterial oxygenation in congenital heart disease. J Paediatr Child Health. 2010. E:1-5.

15. Bin Z, Tiehu Y, Su M, Cun L. Absence of apparent cardioprotection following ischemic preconditioning in immature rabbit hearts. Heart Lung Circ. 2003;12: 39-43.

16. Awad WI, Shattock MJ, Chambers DJ. Ischemic preconditioning in immature myocardium. Circulation. 1998;98:II206-13.

17. Liu H, Cala PM, Anderson SE. Ischemic preconditioning: effects on $\mathrm{pH}, \mathrm{Na}$ and $\mathrm{Ca}$ in newborn rabbit hearts during ischemia/reperfusion. J Mol Cell Cardiol. 1998;30:685-97.

18. Baker JE, Holman P, Gross GJ. Preconditioning in immature rabbit hearts: role of KATP channels. Circulation. 1999;99:1249-54.

19. Ostadal B, Kolar F. Cardiac adaptation to chronic high-altitude hypoxia: beneficial and adverse effects. Respir Physiol Neurobiol. 2007;158:224-36.

20. Tajima M, Katayose D, Bessho M, Isoyama S. Acute ischaemic preconditioning and chronic hypoxia independently increase myocardial tolerance to ischaemia. Cardiovasc Res. 1994;28:312-9.

21. Forkel J, Chen X, Wandinger S, Keser F, Duschin A, Schwanke U, et al. Responses of chronically hypoxic rat hearts to ischemia: KATP channel blockade does not abolish increased RV tolerance to ischemia. Am J Physiol Heart Circ Physiol. 2004;286:H545-51.

22. Schmidt M, Stottrup N, Michelsen M, Nielsen T, Botker HE, Kharbanda R, et al. Adverse effects of remote ischemic preconditioning in the immature heart. Presented at the 5th World Congress of Paediatric Cardiology and Cardiac Surgery, Cairns, Australia, 2009.

23. Jensen HA, Loukogeorgakis S, Yannopoulos F, Rimpiläinen E, Petzold A, Tuominen $\mathrm{H}$, et al. Remote ischemic preconditioning protects the brain against injury after hypothermic circulatory arrest. Circulation. 2011;123:714-21.

24. Ren C, Gao X, Steinberg GK, Zhao H. Limb remote-preconditioning protects against focal ischemia in rats and contradicts the dogma of therapeutic time windows for preconditioning. Neuroscience. 2008;151:1099-103.

25. Saxena P, Bala A, Campbell K, Melon B, d'Udeken Y, Konstantinov IE. Does remote ischemic preconditioning prevent delayed hippocampal neuronal death following transient global cerebral ischemia in rats? Perfusion. 2009;24:207-11.

26. Pedersen KR, Povlsen JV, Christensen S, Pedersen J, Hjortholm K, Larsen SH, et al. Risk factors for acute renal failure requiring dialysis after surgery for congenital heart disease in children. Acta Anaesthesiol Scand. 2007;51:1344-9.

27. Ali ZA, Callaghan CJ, Lim E, Ali AA, Nouraei SA, Akthar AM, et al. Remote ischemic preconditioning reduces myocardial and renal injury after elective abdominal aortic aneurysm repair: a randomized controlled trial. Circulation. 2007; 116:I98-105.

28. Pedersen KR, Ravn HB, Povlsen JV, Schmidt MR, Erlandsen EJ, Hjortdal VE. Failure of remote ischemic preconditioning to reduce the risk of postoperative acute kidney injury in children undergoing operation for complex congenital heart disease: a randomized single-center study. J Thorac Cardiovasc Surg. 2012;143:576-83. 